\title{
Research on the Construction of Enterprise Ecosystem Governance System
}

\author{
Yunfei $\mathrm{Xu}^{1, *}$ Weixuan Meng ${ }^{2}$ Yuan Zhang ${ }^{3}$ Yong Zhang ${ }^{4}$ \\ ${ }^{1,2,3,4}$ State Grid Energy Research Institute Co. LTD, Changping, 102209, Beijing, China \\ *Corresponding author. Email: xuyunfei@sgeri.sgcc.com.cn
}

\begin{abstract}
Ecosystem governance is of great significance for improving the quality and efficiency of enterprise ecosystem development and promoting the sustainable and healthy development of enterprise ecosystem. However, current exploration in the theoretical and practical fields has not formed a methodology system that can efficiently guide enterprises to promote ecosystem governance. This paper fully analyses the importance and particularity of enterprise ecosystem governance, analyses the influencing factors of enterprise ecosystem governance from internal and external perspectives and puts forward the framework and system of enterprise ecosystem governance based on the typical experience of advanced enterprise ecosystem governance, which provides reference for the theoretical and practical research of enterprise ecosystem governance.
\end{abstract}

Keywords: Ecosystem governance, influencing factors, governance system

\section{INTRODUCTION}

With the basic goal of maintaining stable operation of ecosystem, enterprise ecosystem governance is the foundation of healthy development of enterprise ecosystem, which is led by ecosystem core enterprises and participated by all ecosystem members. Based on business laws, contracts, procedures, and agreements, it promotes resource sharing, value creation and risk sharing among members of ecosystem, and jointly promotes the process of new business development incubation and multilateral relationship optimization of cross-domain value chain by formulating, implementing, and optimizing ecosystem operation rules [1].

Great changes have taken place in the internal and external environment for the operation and development of enterprise ecosystem [2]. On the one hand, the uncertainty, complexity, dynamics and fuzziness of the external environment are greatly improved, which increases the external pressure of the operation and development of the enterprise ecosystem. In order to adapt to these dynamic changes, enterprises need to constantly optimize and adjust the operation and development mode of ecosystem. It is urgent to standardize ecosystem operation by establishing ecosystem governance framework and enhance dynamic adaptability by strengthening ecosystem governance to cope with possible external pressures and risk [3]. On the other hand, with the continuous expansion of the enterprise ecosystem and the rapid increase of ecological business and ecological partners, enterprises need to rethink and position their status and role in the ecosystem and rethink the ecosystem layout and operation mode from a strategic development perspective. In addition, it is also necessary to establish and improve the corresponding ecosystem development governance rules, such as how to encourage and strengthen cooperation among different ecological partners. How to carry out effective supervision to reduce ecosystem risk? Balanced benefit distribution and risk prevention and control, etc. All these have put forward higher requirements for enterprises' ecosystem governance ability. Under the guidance of strategic objectives, enterprises need to build an ecosystem governance framework suitable for their own development, with clear ecosystem governance objectives, mechanisms and strategies to deal with possible governance problems in the process of operation and development of enterprise ecosystem, so as to continuously improve the quality and efficiency of enterprise ecosystem development. 
The healthy development of enterprise ecosystem is an important factor to measure the ability of enterprise ecosystem governance. One of the goals of enterprise ecosystem management is to reduce ecosystem risk and promote the healthy development of ecosystem. No matter which stage the enterprise ecosystem is in, it is of great significance to strengthen the governance of the ecosystem to maintain its healthy development.

The development of ecosystem has multiplied the potential risk faced by member enterprises. At present, the ecosystem development of enterprises faces more risk in reputation, compliance and finance. The reason lies in the more complex and integrated business ecosystem environment, and the supply chain, distribution channels and more flexible business cooperation and platform mode bring more unpredictable emerging risk. In addition, due to the diversity and complexity of ecological partners, it is far from enough for enterprises to do their own risk prevention and control. Integrating their own risk management into the risk management of ecosystem and maintaining the healthy development of ecosystem together with ecological partners will be an unavoidable important issue in enterprise ecosystem governance. Deloitte conducted an in-depth study of 300 enterprises in Shanghai and Shenzhen stock indexes and found that enterprises were influenced by various close and loose partners, competitors, malicious competitors, compliance regulators and new media in the ecosystem. TMT (including Internet), consumption, manufacturing, finance, medical care and health, energy, government public affairs and real estate industries were all without exception. Crisis events caused a sharp decline in business performance, and a shock wave was enough to destroy an enterprise. Therefore, enterprises must put ecosystem governance in a prominent position, by strengthening risk prevention and control, maintain a good environment for enterprise ecosystem development, and promote ecosystem healthy development. Therefore, ecosystem governance breaks through the previous model of leading enterprises leading the governance process, and relies on all ecosystem members to participate in the governance process [3].

\section{INFLUENCING FACTORS OF ENTERPRISE ECOSYSTEM GOVERNANCE}

Enterprise ecosystem governance is not only affected by external environment such as resource elements, technological breakthrough and risk prevention and control, but also depends on the comprehensive effect of internal factors such as its ecosystem development stage, enterprise positioning and business development characteristics [4].

\subsection{External Influencing Factors}

The impact of external environment on ecosystem governance is reflected in resource elements, technological breakthroughs and risk prevention and control.

In terms of resource elements, an important concern in ecosystem governance lies in the aggregation ability of resource elements formed by ecosystem, that is, whether ecological partners can provide resource elements for sustainable development and growth of ecosystem. This determines whether the enterprise ecosystem governance should focus on internal business adjustment, resource integration and factor agglomeration, or pay more attention to external market demand and open up new market opportunities. Resource elements have an impact on ecosystem governance by determining the functional orientation of enterprise ecosystem.

In terms of technological breakthroughs, with the development and application of new technologies such as big data, cloud computing, Internet of things and so on, the technological environment facing the development of enterprise ecosystem has made great breakthroughs. The integration of new technologies with the operation and development of the ecosystem is getting closer and closer, which has a greater impact on the business of enterprises in the ecosystem. At the same time, with the help of new technology, the ecosystem governance mode has also changed from offline to online and offline integration, and the governance ideas should be adjusted accordingly.

In terms of risk prevention and control, the complexity and dynamics of the external environment are constantly improving, and the external risk factors are also growing, so are the risk challenges faced by enterprise ecosystem governance. Internally, the development of ecosystem makes enterprises and ecological partners closely linked, which is mutually beneficial and symbiotic, but also needs to share risk. Due to the diversity and complexity of ecological partners, the risk in ecosystem development also increase exponentially. Ecosystem governance needs to combine its own risk management with the risk prevention and control of ecosystem.

\subsection{Internal Influencing Factors}

The influence of internal factors is mainly reflected in the influence of differences in development stage, enterprise positioning and business characteristics on ecosystem governance.

In terms of development stage, in different ecosystem development stages, the focus of enterprise ecosystem governance will change accordingly. In the stage of ecosystem construction, the focus of ecosystem 
governance is to aggregate resource elements, and attract different ecological partners to join in by establishing a benefit sharing mechanism to integrate into the process of industrial development and business collaboration, and gradually expand business boundaries. In the stage of ecosystem utilization, the focus of ecosystem governance needs to pay more attention to the integration and innovation at the business level, and carry out business model changes to expand market influence; At the same time, comprehensive evaluation from a strategic point of view can identify the availability of different business ecosystems, increase the success rate of business model reform and innovation, and expand the ecosystem boundary of the company. In the stage of ecosystem management, ecosystem governance needs to pay attention to ecosystem availability, health and cohesion, and strengthen risk prevention and control.

In terms of enterprise positioning, the positioning of enterprises in the ecosystem determines the degree of participation of enterprises in ecosystem governance. If one position oneself as the core enterprise in the ecosystem or play a leading role in the ecosystem, then ecosystem governance is not limited to the platform construction and business management of the enterprise itself, but needs to systematically consider many factors such as business layout, resource element allocation, benefit distribution and risk prevention and control from the perspective of the whole ecosystem development, leading to promote the development of the ecosystem and guiding to strengthen ecosystem governance. If the enterprise is only one of the participants in many ecosystems, the key point of enterprise ecosystem governance is to abide by ecosystem governance rules and cooperate with ecological partners to do core business management and risk prevention and control.

In terms of business characteristics, the business characteristics of enterprises are closely related to their ecosystem governance strategies. For traditional businesses, the focus of enterprise ecosystem governance lies in improving quality and efficiency by optimizing resource allocation and establishing cooperative relations, forming cost advantages and economies of scale; For emerging businesses, the focus of enterprise ecosystem governance will focus more on attracting ecological partners to join, exploring potential market opportunities to expand the market, and forming a community of interests sharing benefits and risk with ecological partners; For businesses with stable development, the focus of enterprise ecosystem governance will focus on risk prevention and control, so as to reduce system risk and maintain good ecosystem development prospects.

According to the Deloitte 2014 Global Outsourcing Trends report, the top five global entrepreneurs commonly use ecosystem cooperation governance tools including: partner financial performance management, contract management, governance and integrity management, service level inspection, and dispute management; At the same time, the headache caused by the lack of advanced management methods includes supervision in the transformation of partners, third-party customer demand management, integration of diverse partners, risk management and third-party compliance, and intelligent document management. First-class enterprises pay great attention to ecosystem governance actions, but $72 \%$ of the enterprises participating in the survey admit that they lack relevant management tools and skills, $49 \%$ of them are in urgent need of relevant talents, and they are confused about how to make the business and functional departments clear their roles and cooperate and share with each other.

\section{TYPICAL EXPERIENCE OF ECOSYSTEM MANAGEMENT IN ADVANCED ENTERPRISES}

Through combing the typical practices of ecosystem development and governance of advanced enterprises such as Alibaba, Haier, Xiaomi, Tencent and Aerospace Cloud Network, this paper summarizes the typical experiences of these advanced enterprises in ecosystem governance.

Firstly, to strengthen the construction of enterprise ecosystem digitalization, promote the online of all links, and improve the ecosystem connection and operational efficiency. Ali positioned himself as a network technology company, taking technology as the core and data value mining as a means, promoting the digital transformation of related industries from the retail industry, and sharing economic benefits in the process of improving the operational efficiency of the industry. Empower platform business based on network and information communication technology, precipitate online data through online real-time connection, carry out data analysis, prediction, decision-making and business innovation, and further strengthen the "core" of platform business ecosystem. Haier expanded its online to offline based on COSMOPlat and realized the realtime interaction between users and production by using network and information technology, which made production driven by users' needs, promoted the traditional linear production mode to a nonlinear mass customization mode, and significantly improved the production efficiency and the ability to meet users' needs. This enlightens enterprises to speed up the digital transformation, promote the online integration and integration of data, information and resources, and enhance the ecosystem digital connectivity in the process of ecosystem governance. 
Secondly, to establish a mutually beneficial and symbiotic ecosystem development operation mechanism through resource sharing and value distribution. Through resource sharing, we will continue to attract outstanding enterprises from various fields to join the enterprise ecosystem, expand the business field and ecosystem map, and make the market bigger and stronger. Through value distribution, the interests of ecological partners and the interests of enterprises are bound together to encourage ecological partners to create a win-win situation. Xiaomi's ecosystem construction and governance mode is "investment+incubation", and Xiaomi transfers all its resources such as talent team, brand, user group, ecommerce platform, supply chain capability, capital, reputation, product experience and brand popularity to ecosystem chain enterprises. Three-dimensional linking and sharing of resources make excellent ecosystem enterprises spring up, grow and expand, which in turn further stabilizes the ecosystem foundation of millet, supplies each other and creates value for each other, forming a virtuous circle of ecosystem system. Through a reasonable benefit-sharing mechanism, Tencent distributed 20 billion yuan, which is equivalent to its annual income at that time, to its partners in the first stage, so as to stimulate the vigorous development of the entire Internet ecosystem, create the largest and most divided open platform, and support all partners to "recreate a Tencent".

Thirdly, to promote the ecosystem integration and development of business on all platforms through crossborder integration and collaborative innovation. Ali takes mobile payment as the main line and builds $\mathrm{N}$ application innovation systems based on the "1+2+2+N" technical architecture, namely, a unified Alibaba Cloud platform base, a data middle station and a business middle station, a mobile server and an office terminal represented by Alipay and Nail, and integrates the ecosystem of maps and logistics on this basis to better serve the digital transformation of vertical industries. Aerospace Cloud Network is to build an open innovation system with equal emphasis on multiple channels, use the strategy of "taking a big ship and going out to sea", and realize more and more open and international technological innovation through direct purchase of technology, patent cross-licensing, cooperation and interaction with related enterprises, universities and scientific research institutions in the industrial chain, and active participation in the formulation of international standards.

Fourthly, to pay attention to the safety and legal risk in ecosystem governance. Protecting users' interests under the background of opening is always one of the most important issues in ecosystem governance. Advanced research is based on the legal issues brought by user data expansion and new business development, clarifying the boundaries of data collection, application and sharing, and avoiding and preventing risk in advance. Tencent has zero tolerance for any behavior that harms users' interests. Ensure that users' interests will not suffer losses due to bad behaviors such as hacking, fishing and fraud. Any behavior that steals user data and endangers the safety of user property is absolutely intolerable by Tencent's open platform, which is Tencent's high-voltage line. Industrial Internet platforms such as Aerospace Cloud Network have been deeply aware of the importance of data security at the beginning of its establishment, and regard safety and compliance as the foundation of digital ecosystem. The cross-border data sharing of industrial enterprises poses a greater security challenge, which not only affects the operation of industrial production, but even leads to production safety accidents and endangers national security.

\section{CONSTRUCTION OF ENTERPRISE ECOSYSTEM GOVERNANCE SYSTEM}

The enterprise ecosystem is a process in which many stakeholder groups create a win-win situation through cooperation. In this process, it is necessary to gradually establish an ecosystem governance system to restrain, encourage and govern all stakeholders, so as to coordinate, standardize and develop the ecosystem healthily. Enterprise ecosystem governance system is a framework of ecosystem governance mechanism and governance strategy formed around the objectives and concepts of enterprise ecosystem governance. Enterprise ecosystem governance is based on laws, contracts, rules and procedures to promote resource sharing, value creation and risk sharing among members of the ecosystem, and jointly promote the incubation of new business development and cross-domain value chain integration. The basic elements of enterprise ecosystem governance include governance objectives, governance mechanisms and governance strategies.

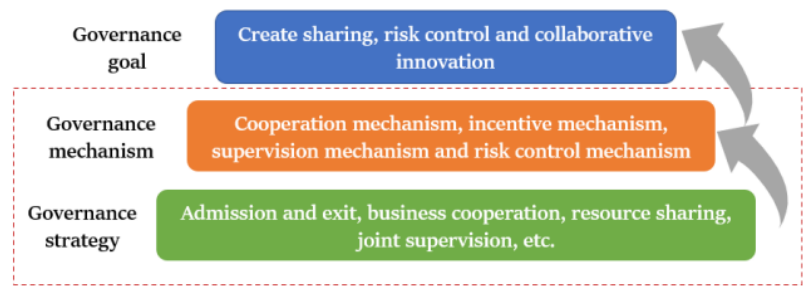

Figure 1 Enterprise ecosystem governance system

The goal of enterprise ecosystem governance is the foundation of enterprise ecosystem governance, which originates from the coupling relationship of co-creation, sharing, deep interaction and common evolution among members of the ecosystem, mainly including customercentered, equal and open, and mutually beneficial sharing. The core of enterprise ecosystem governance 
lies in establishing an effective governance mechanism to effectively coordinate, restrain and motivate the members of the ecosystem. Enterprise ecosystem governance mechanism is a norm and criterion that can restrict and coordinate the interests among ecosystem members and ensure the healthy and stable operation of ecosystem, which mainly includes cooperation mechanism, incentive mechanism, supervision mechanism and risk control mechanism. Ecosystem governance strategy is the concrete embodiment of ecosystem governance mechanism, which mainly includes the specific measures taken in ecosystem governance, such as admission, business cooperation, resource sharing and joint supervision. Main mechanisms and corresponding strategies are as follows:

\section{(1) Supervision mechanism}

Membership admission: to establish a qualification examination and certification system and conduct credit review.

Joint supervision: to set up a supervision institution to supervise fraud and dishonesty and build a good ecosystem reputation.

Evaluation of rewards and punishments: to formulate rules for mutual evaluation and rewards and punishments and punish vicious competition and dishonesty.

Member withdrawal: to introduce substitute members, reducing the business relevance of inferior partners, and implementing the last elimination system.

(2) Cooperative mechanism

Equity investment: it is suitable for enterprises with high asset specificity such as knowledge-intensive and technology-intensive.

Long-term contract: it is suitable for enterprises with low asset specificity, full market competition and low measurement cost

Joint incubation: to integrate scarce resources of all parties and jointly carry out product and project R\&D incubation.

(3) Incentive mechanism

Platform empowerment: includes comprehensive service empowerment, financial empowerment, intangible assets empowerment, supply chain empowerment, data empowerment, technology empowerment, etc.

Cross-selling: to share customer relationship and sell products together.

Benefit distribution: to sign an agreement on income pricing, risk sharing and profit sharing, establish distribution procedures and standards, and ensure open and fair benefit distribution.
(4) Risk control mechanism

Business risk control: with the help of information prediction, to timely identify and prevent the business risk of members' credit, out-of-stock, cash flow break and inferior products.

Information risk control: to establish alliance between data factors and intellectual property protection, strengthen security protection of data platform and network, and promote open and transparent release of information.

Legal risk control: to continuously carry out research on policies and regulations, and timely investigate and deal with violations of laws and regulations.

\section{CONCLUSION}

In recent years, ecosystem development has become the mainstream of Internet enterprises, and has been proved to be an important strategic means to adapt to environmental changes and promote transformation and upgrading. Implementing ecosystem development is a strategic choice for enterprises to change their own development model, which can help enterprises break through resource boundaries, quickly complement their capabilities, better meet customer needs and play a leading role in changing environment [5]. By defining the goal of enterprise ecosystem governance, establishing governance mechanism and perfecting governance strategy, the enterprise ecosystem governance system is continuously optimized to promote the healthy and sustainable development of enterprise ecosystem.

\section{ACKNOWLEDGMENTS}

This research was supported by the Self-research Project of State Grid Energy Research Institute Co., Ltd. "Research on Evolution and Development Model and Key Technologies of Corporate Energy Internet Ecosystem Supporting Corporate Strategy" (Project No. 526700200009).

\section{REFERENCES}

[1] W. Han, J. Yang, X.H Hu, Y.L Zhang, FW Chen. How does business model innovation shape the attribute difference of business ecosystem? -Crosscase longitudinal research and theoretical model construction based on two new ventures[J]. Management World, 2021, 37(01):88-107+7.

[2] S. Zheng, HJ Wang. Structure and evolution mechanism of enterprise innovation ecosystem under modularization: a longitudinal case study of Haier group from 2005 to 2019[J]. Scientific Research Management, 2021, 42(01):33-46. 
[3] M. Jain, S. Dhir, T. Khoa. TISM modelling of social enterprise ecosystem: a study in Indian context[J]. Journal for Global Business Advancement, 2021, 13(5).

[4] W. Tang. Research on the Construction Mechanism of Innovation Ecosystem of Small and Mediumsized Sci-tech Enterprises[J]. Research on Technology Economy and Management, 2021(03):35-39.

[5] S. Andrew, G. Annabelle. Integrating Research on Interorganizational Networks and Ecosystems[J]. Academy of Management Annals, 2020 (1). 